\title{
Isolation and identification of a new flavonoid glycoside from Carrichtera annua L. seeds
}

\author{
Abdelaaty A. Shahat ${ }^{1}$, Khaled A. Abdelshafeek ${ }^{1,2}$, Husseiny A. Husseiny ${ }^{3}$ \\ ${ }^{1}$ Department of Phytochemistry, National Research Center, Dokki, Cairo, ${ }^{2}$ Department of Chemistry, Sirt University, Sirt, Libya, ${ }^{3}$ Department of \\ Pharmacognosy, College of Pharmacy, Misr University of Science and Technology (MUST), 6th of October City, Egypt
}

Submitted: 25-02-2011

Revised: 19-04-2011

Published: 16-09-2011

A B S TR A C T

Background: Flavonoids are a major group of constituents and are assumed to be among the beneficial components. Recently, they have also received considerable interest as components of foodstuffs and nutraceuticals because of their antioxidant and anticancer properties. Materials and Methods: About $500 \mathrm{~g}$ of air-dried powdered seeds of $C$. annua were defatted seeds and extracted with $70 \%$ methanol. The combined methanol extract was partitioned with chloroform and $n$-butanol. The butanol extract was concentrated and subjected to column chromatography on polyamide. Results: The fraction eluted with aqueous methanol ( $40 \%$ and $50 \%$ ) was found to contain three main flavonoids $(1,2$, and 3$)$. Repeated column chromatography on polyamide and Sephadex LH-20 gave compound 1. Compounds 2 and 3 were further purified using preparative paper chromatography with 20\% HOAc and Sephadex LH-20 column. Conclusions: Reinvestigation of the flavonoidal constituents of the butanol fraction of the aqueous methanolic extract of Carrichteraannua seeds led to isolation and identification of a new flavonoidal glycosidenamed as quercetin 3-O-[(6-sinapoyl- $\beta$-glucopyranosyl)-(1-2)- $\beta$-arabinopyranosyl]-7-O- $\beta$-glucopyranoside 1 , in addition to, quarecetin-3-O-glucoside 2, isorhamnetin-3-O- $\beta$-runtinoside3, and isorhamnetin4. Structures of the isolated compounds were established by UV, MS, and ${ }^{1} \mathrm{H}$ and ${ }^{13} \mathrm{C} N M R$.

Key words: Acylated flavonoid, brassicaceae, Carrichtera annua

\section{INTRODUCTION}

The family Brassicaceae (= Cruciferae) consists of 350 genera and about 3500 species, and includes several genera such as Camelina, Crambe, Sinapis, Thlaspi, and Brassica. The genus Brassica is the most important one within the tribe Brassiceae, which includes some crops and species of great worldwide economic importance such as Brassica oleracea L., Brassica napus L., and Brassica rapa L. The same species can be utilized for several uses according to different forms or types. The genus is categorized into oilseed, forage, condiment, and vegetable crops by using their buds, inflorescences, leaves, roots, seeds, and stems. Brassicaceae vegetables represent an important part of the human diet worldwide, and are consumed by people all over the world. ${ }^{[1]}$ The largest genera are Draba (365 species),

Address for correspondence:

Prof. Abdelaaty A. Shahat, Department of Phytochemistry,

National Research Centre, Bohouth Street, 12311 Dokki, Giza,

Egypt. E-mail: aashahat@hotmail.com
Cardamine (200 species), Erysimum (225 species), Lepidium (230 species), and Alyssum (195 species). Numerous species have food economic importance such as cabbage, cauliflower, turnip, and rape. ${ }^{[2]}$ The species are utilized as salad plants due to their content of anti-scorbutic and low content of erucic acids. Many Cruciferous species are known for their use in folk medicine for the treatment of snake bites. Moreover, they are used as an antimicrobial agent for relief of biliary colic and wound sores. They have enhancing the detoxification effect of chemical carcinogen and some species exhibit hypoglycemic and hypotension effects. ${ }^{[3,4]}$ Carrichtera annua is an endemic annual herb belonging to a family belonging to the Cruciferae (or Brassicaceae), growing up to $40 \mathrm{~cm}$ specially in north Sinai at Elarrish region, Egypt. C. annua in particular is known to be used by the native Bedouins as an antidiabetic and antispasmodic. Flavonoids are a major group of constituents and are assumed to be among the beneficial components. Recently, they have also received considerable interest as components of foodstuffs and nutraceuticals because of their antioxidant and anticancer 
properties. ${ }^{[5-7]}$ The flavonoidal fraction of the seeds of C. annua, was investigated using LC/ESI-MS and nanoESI-MS/CID/MS. The flavonoidal fraction was found to contain 12 flavonol $O$-glycosides, which were structurally related and of which 11 were acylated with one or more benzoyl, feruloyl, or sinapoyl groups ${ }^{[8]}$ In a previous study different known and new flavonoids compounds were isolated from the seeds and the herb and investigated by LC/MS and or NMR. ${ }^{[8-10]}$ In this study, we report the isolation and structure elucidation of a new acylated flavonol triglycoside.

\section{MATERIALS AND METHODS}

\section{Plant material}

The plant was collected from Al-Arish region, Sinai, Egypt in April 2008 during the seedling stage. The plant was collected and identified as described previously. ${ }^{[8]}$

\section{Apparatus and techniques}

All NMR spectra were run on a Bruker DRX-400 instrument operating at $400 \mathrm{MHz}$ for ${ }^{1} \mathrm{H}$ and at 100 $\mathrm{MHz}$ for ${ }^{13} \mathrm{C}$, using standard pulse sequences. Chemical shifts are reported on the $\delta$ scale in parts per million downfield from TMS. TLC was carried out on precoated Silica gel $60 \mathrm{~F}_{245}$ plates (Merck), developed with EtOAcHOAc- $\mathrm{HCOOH}-\mathrm{H}_{2} \mathrm{O}$ (30:0.8:1.2:8, v/v, upper phase (solvent 1), and 100:10:10:20) (solvent 2) and Neu's spray reagent ( $1 \%$ diphenylboric acid ethanolamine complex). Column chromatography was performed on Silica gel (Merck), polyamide 6S (Riedel, De Haën), and Sephadex LH-20 (Pharmacia).

\section{Extraction and isolation of flavonoids}

About $500 \mathrm{~g}$ of air-dried powdered seeds of C. annua were extracted with petroleum ether (br. $40-60^{\circ} \mathrm{C}$ ) by maceration $(1.2 \mathrm{~L} \times 4)$. The defatted seeds were extracted with methanol $(70 \%)$ for 3 days $(1.5 \mathrm{~L} \times 3)$. The combined methanol extract was evaporated under reduced pressure at $45^{\circ} \mathrm{C}$ and the residue dissolved in hot distilled water $(400 \mathrm{ml})$ and left in the refrigerator overnight and filtered the precipitated matters. The filtrate was partitioned with chloroform $(500 \mathrm{ml} \times 2)$ and $n$-butanol $(600 \mathrm{ml} \times 4)$. The butanol extract was concentrated and subjected to column chromatography (CC) on polyamide. Elution was started with distilled water and decreasing the polarity in 10\% with methanol to $100 \%$ methanol. The fractions were collected by monitoring on thin layer chromatography (TLC) using solvent 1 and/or solvent 2 as developing solvents. The fraction eluted with aqueous methanol ( $40 \%$ and $50 \%$ ) was found to contain three main flavonoids $(1,2$, and 3$)$, this fraction was subjected again to CC using
$30 \%$ methanol for elution and increasing methanol to $70 \%$ as mentioned above. Compound 1 was isolated and purified by using Sephadex LH-20 column eluted with methanol to give $22 \mathrm{mg}$ of compound 1 . Compounds 2 and 3 were further purified using preparative paper chromatography with 20\% HOAc and passing over a small Sephadex LH-20 column using methanol as eluent (compound 2 was $18 \mathrm{mg}$ and compound 3 was $16 \mathrm{mg}$, respectively). Compound 4 was isolated from the fraction eluted with $70 \%$ methanol (polyamide column) in the same manner to afford (10 mg).

\section{RESULTS AND DISCUSSION}

The flavonoidal compounds were obtained from the $n$-butanol soluble fraction of the defatted aqueous methanol of $C$. annua powdered seeds. Acid hydrolysis of these compounds yielded quercetin and isorhamnetin as aglycones and arabinose and glucose as sugars. Compound 1 was isolated as an amorphous yellow substance, and its ${ }^{1} \mathrm{H}$ and ${ }^{13} \mathrm{C}$ NMR spectra showed the presence of a quercetine moiety, three sugar residues, sinapoyl moiety and two methoxyl groups. The chemical shifts of C-2 and C-3 ( $\delta 156.9$ and 135.2 , respectively) indicated C-3 substitution of the quercetin moiety. ${ }^{[1]}$

The ${ }^{1} \mathrm{H}$ NMR spectrum showed, in the aromatic region, a pair of meta coupled doublets at $\delta 6.28$ and $\delta 6.21(J=1.6$ $\mathrm{Hz}$ ), which were attributed to $\mathrm{H}-6$ and $\mathrm{H}-8$ of quercetin (A-ring), respectively, and the typical three-spin system of the 1,3,4-trisubstituted B-ring: a meta coupled doublet at $\delta$ $7.50(J=2 \mathrm{~Hz})\left(\mathrm{H}-2^{\prime}\right)$, an ortho-coupled doublet at $\delta 6.79$ $(J=8.8 \mathrm{~Hz})\left(\mathrm{H}-5^{\prime}\right)$, and an ortho and meta coupled doublet of doublets at $\delta 7.55(J=8.8,2 \mathrm{~Hz})\left(\mathrm{H}-6^{\prime}\right)$. Substitution of quercetin in the position C-3 was evident from the chemical shift of C-2 ( $\delta 156.9)$, whereas in flavonols with an unsubstituted hydroxyl functionality at this position C-2 is expected around $\delta 147 .{ }^{[12]}$

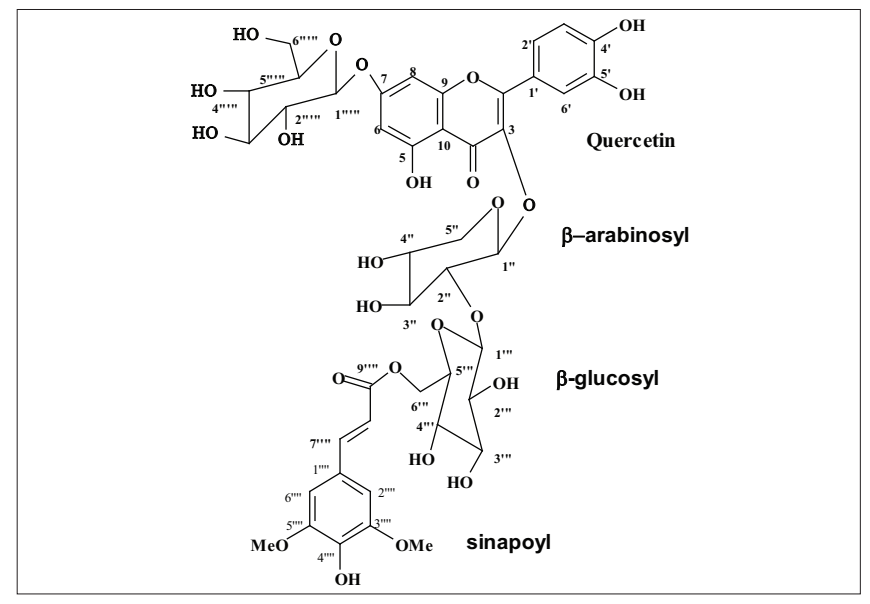

Compound 1 
The signal at $\delta 161.9$ was assigned to C-5 and the assignment of C-6 and C-8 was confirmed through the long range coupling observed in the HMBC experiment with the ${ }^{1} \mathrm{H}$ NMR signal at $\delta 6.28(\mathrm{H}-6)$ while the signal at $\delta 164.8$ showed correlations to both H-6 and H-8 $(\delta 6.1)$ so the signal at 164.8 was assigned for $\mathrm{C}-7$, compound 1 was a 3,7 di-substituted quercetin. The 2D NMR spectra allowed the assignment of all signals of the glucose moiety at C-7 which could be identified as a glucopyranoside ${ }^{[13]}$ and the $\beta$ configuration of the anomeric carbon was cleared from the coupling constant of $\mathrm{H}-1^{\prime \prime \prime \prime \prime \prime \prime}(J=7.5 \mathrm{~Hz})$ observed in the ${ }^{1} \mathrm{H}$ NMR spectrum. ${ }^{[14]}$ The presence of a sugar moiety at C-7 was further confirmed through the UV spectra of both the compound and it's aglycone after acid hydrolysis where band-II showed bathochromic shift $(10 \mathrm{~nm})$ in the sodium acetate spectrum of the aglycone and does not occur in the compound itself ${ }^{[13]}$. In fact, the UV spectra with different shift reagents proved the presence of quercetin moiety with free hydroxyl groups at C-3', C-4', C-5, and substituted at $\mathrm{C}-3$ where band-I $(\mathrm{MeOH})$ appeared at 335 $\mathrm{nm}$. ${ }^{[9]}$. Two methoxy groups appeared in ${ }^{1} \mathrm{H}$ NMR at $\delta 3.7$ which correlated to C- $3^{\prime \prime \prime \prime}$ and $\mathrm{C}-5^{\prime \prime \prime \prime} \cdot{ }^{13} \mathrm{C}$ NMR at $\delta 148.5$. The C-7"'"-C-8"'"' double bond showed a large coupling constant $(J=14.9 \mathrm{~Hz})$ which prove the trans-configuration of the double bond. The carbonyl group of the sinapoyl moiety occurring at $\delta 168.3$ exhibited a long range ${ }^{13} \mathrm{C}-{ }^{1} \mathrm{H}$ correlation with a ${ }^{1} \mathrm{H}$ NMR signal at $\delta 4.11$ assigned to one of the H-6"'"' proton of a hexose unit representing the second glucose moiety. The anomeric proton at $\delta 4.55$ showed a long range correlation with a ${ }^{13} \mathrm{C}$ NMR signal at $\delta 81.9$ correspond to the proton at $\delta 4.19$ in the HSQC spectrum. The anomeric proton $\mathrm{H}-1$ " of arabinose was assigned at $\delta 5.52$, so we can conclude that the glucose moiety is attached at $\mathrm{C}-2^{\prime \prime}$ in arabinose. All data of ${ }^{1} \mathrm{H}$ and ${ }^{13} \mathrm{C}$ were presented in Table 1 . The FAB mass spectrum of the compound displayed a molecular ion peak at $\mathrm{m} / \mathrm{z}$ $987[\mathrm{M}+\mathrm{Na}]^{+}$which is compatible with the molecular formula $\mathrm{C}_{43} \mathrm{H}_{48} \mathrm{O}_{25}$, this can confirm the presence of two hexose moieties, pentose moiety, and sinapoyl moiety attached to quercetin nucleus. The presence of the sinapoyl moiety was confirmed through the peak at $m / z 207$ and its fragments (at $m / z=192,175)$ also the ion peak at $m / z$ 523 attributed to $\left[\mathrm{Na}^{+}\right.$sinapoyl-hexose-pentose] part which attached to quercetin at $m / z 303$. The terminal hexose can be deduced from the ion at $m / ₹ 803$ which matched with $\left[\mathrm{M}^{+}+\mathrm{H}-162\right]^{+}$. Since the loss of sinapoyl-hexose-pent part $(\mathrm{m} / \mathrm{z} 465)$ is much more pronounced than the loss of terminal hexose (at $m / z$ 803) so, we can conclude that these parts are at C-3 and C-7. ${ }^{[8]}$ These spectral data were in good agreement with those reported for quercetin 3-O-[(6feruloyl- $\beta$-glucopyranosyl)-( $1 \rightarrow 2)-\beta$-arabinopyranoside] -7-O- $\beta$-glucopyranoside which was isolated before from

\begin{tabular}{|c|c|c|c|c|c|}
\hline $\begin{array}{l}\text { C } \\
\text { no. }\end{array}$ & $\begin{array}{c}13 \mathrm{C} \\
(\mathrm{ppm})\end{array}$ & $\begin{array}{c}\text { 1H (ppm), } \\
\text { multi., } \\
\mathrm{J}(\mathrm{Hz})\end{array}$ & $\begin{array}{c}\text { Carbon } \\
\text { no. }\end{array}$ & $\begin{array}{c}13 C \\
(p p m)\end{array}$ & $\begin{array}{c}1 \mathrm{H} \\
\text { (ppm), } \\
\text { multi., } \\
\mathrm{J}(\mathrm{Hz})\end{array}$ \\
\hline 2 & 156.9 & & \multicolumn{3}{|c|}{ Sinapoyl } \\
\hline 3 & 135.2 & & $1^{\prime \prime \prime \prime}$ & 125.86 & \multirow{3}{*}{$6.2, \mathrm{~s}$} \\
\hline 4 & 179.2 & & $2^{\prime \prime \prime \prime}$ & 105.9 & \\
\hline 5 & 161.9 & & $3^{\prime \prime \prime \prime}$ & $148.5 \mathrm{j}$ & \\
\hline 6 & 100.0 & $\begin{array}{l}\text { 6.28, d, } 1.6 \\
\text { (meta) }\end{array}$ & $4^{\prime \prime \prime \prime}$ & 138.95 & \\
\hline 7 & 164.8 & & $5^{\prime \prime \prime \prime}$ & 148.5 & \\
\hline 8 & 94.2 & $\begin{array}{l}6.1, \mathrm{~d}, 1.6 \\
\quad(\text { meta })\end{array}$ & 6"'"' & 105.9 & $6.2, s$ \\
\hline 9 & 157.3 & & $7^{\prime \prime \prime \prime}$ & 146.4 & $\begin{array}{c}7.1, \mathrm{~d} \\
15.2\end{array}$ \\
\hline 10 & 104.9 & & $8^{\prime \prime \prime \prime}$ & 114.8 & $\begin{array}{c}5.65, \mathrm{~d}, \\
15.5\end{array}$ \\
\hline $1^{\prime}$ & 121.8 & & $9^{\prime \prime \prime \prime}$ & 168.0 & \\
\hline $2^{\prime}$ & 116.7 & $\begin{array}{l}7.52, \mathrm{~d}, 2 \\
\text { (meta) }\end{array}$ & $2 \mathrm{CH} 3 \mathrm{O}-$ & 56.12 & $\begin{array}{l}\text { Sharp } \\
3.8, \mathrm{~s}\end{array}$ \\
\hline 3 & 145.3 & \multicolumn{4}{|c|}{ 7-O-glucosyl } \\
\hline $4^{\prime}$ & 149.1 & & $1^{\prime \prime \prime \prime \prime}$ & 101.1 & $\begin{array}{l}5.1, \mathrm{~d} \\
6.9\end{array}$ \\
\hline $5^{\prime}$ & 115.8 & $\begin{array}{l}6.95, \mathrm{~d}, 8.8 \\
\text { (ortho) }\end{array}$ & $2^{\prime \prime \prime \prime \prime}$ & 74.1 & $3.23, \mathrm{~m}$ \\
\hline $6^{\prime}$ & 122.58 & $\begin{array}{c}\text { 7.32, dd 8.8, } 2 \\
\text { (ortho, meta) }\end{array}$ & $3^{\prime \prime \prime \prime \prime}$ & 77.23 & $3.1, \mathrm{~m}$ \\
\hline \multicolumn{2}{|c|}{ 3-O-arabinosyl } & & $4^{\prime \prime \prime \prime \prime}$ & 70.3 & $3.3, \mathrm{~m}$ \\
\hline $1^{\prime \prime}$ & 100.35 & $5.52, \mathrm{~d}, 3.5$ & $5^{\prime \prime \prime \prime \prime}$ & 78.05 & $3.45, \mathrm{~m}$ \\
\hline $2^{\prime \prime}$ & 81.9 & $\begin{array}{c}4.19, \mathrm{dd}, 5.5 \\
3.5\end{array}$ & $6^{\prime \prime \prime \prime \prime}$ & 61.4 & $\begin{array}{c}3.6 \\
\text { dd, } 10.5 \\
7.9\end{array}$ \\
\hline $3^{\prime \prime}$ & 71.5 & $3.9, \mathrm{~d}, 5.4$ & & & \\
\hline $4 "$ & 66.92 & $3.77, \mathrm{~m}$ & & & \\
\hline $5^{\prime \prime}$ & 63.2 & $\begin{array}{c}3.9, \mathrm{~m}, 3.25 \\
\mathrm{~m}\end{array}$ & & & \\
\hline \multicolumn{6}{|c|}{ 3-O-glucosyl } \\
\hline $1^{\prime \prime \prime}$ & 105.95 & $4.55, \mathrm{~d}, 8$ & & & \\
\hline $2^{\prime \prime \prime}$ & 75.2 & $3.19, \mathrm{~m}$ & & & \\
\hline $3^{\prime \prime \prime}$ & 77.52 & $\begin{array}{c}3.35, \mathrm{dd}, 8.5 \\
8.5\end{array}$ & & & \\
\hline $4^{\prime \prime \prime}$ & 71.9 & $3.18, \mathrm{~m}$ & & & \\
\hline $5^{\prime \prime \prime}$ & 74.98 & $\begin{array}{c}3.45, \mathrm{dd}, 7.6 \\
7.4\end{array}$ & & & \\
\hline 6"' & 63.85 & $4.5, \mathrm{~m}$ & & & \\
\hline
\end{tabular}

the herb of this plant. ${ }^{[9]}$

From all the previous data we can conclude the structure of compound 1 as quarecetin-3-O [(6-sinapoyl- $\beta$ glucopyranosyl $(1 \rightarrow 2)-\beta$-arabinopyroside]-7-Oglucopyranoside, which is considered as a new compound. The other three compounds were identified as quarecetin3-O-glucoside, isorhamnetin-3-O-runtinoside, and isorhamnetin by comparison with the literature data. ${ }^{[10-12]}$ It is evident to note that the compound isorhamnetin -3-O-runtinoside was isolated before from the herb of this plant. ${ }^{[10]}$ 


\section{REFERENCES}

1. Cartea ME, Francisco M, Soengas $P$, Velasco P.Phenolic compounds in Brassica vegetables. Molecules 2010;16:251-80.

2. Carlquist S. Wood anatomy of Macaronesian and other Brassicaceae. Aliso1971;7:365-84.

3. Hall JC, Sytsma KJ, Iltis HH. Phylogeny of Capparaceae and Brassicaceae based on chloroplast sequence data. Am J Bot 2002;89:1826-42.

4. Nawal H, Mohamed L, Atta EM. Chemical Constituents of Desc-urainiasophiaL. and its Biological Activity Rec. J Nat Prod 2009;3:58-67.

5. Pietta PG. Flavonoids as antioxidants. J Nat Prod 2000;63: 1035-42.

6. Crozier A, Burns J, Aziz AA, Stewart AJ, Rabiasz HS, Jenkins GI, et al. Antioxidant flavonols from fruits, vegetables and beverages: Measurements and bioavailability. Biol Res 2000;33:79-88.

7. Shahat AA, Cos P, Hermans N, Apers S, De Bruyne T, Pieters $\mathrm{L}$, et al. Anti-complement and antioxidant activities of new acetylated flavonoid glycosides from Centauriumspicatum. Planta Med 2003;69:1153-6.

8. Cuyckens F, Shahat AA,Van den Heuvel H, Abdel-Shafeek KA, El-Messiry MM, Seif-El Nasr MM, et al. The application of liquid chromatog-raphy-electrospray ionization mass spectrometry and collision -induced dissociation in structural characterization of acylatedflavonol -O-glycosides from the seeds of Carrichtera annua. Eur J Mass Spectrom (Chichester, Eng) 2003;9:409-20.

9. Abdel-Shafeek KA, El-Messiry MM, Shahat AA, Apers S, Pieters L, Seif-El Nasr MM. A new acylatedflavonoltriglycoside from Carrichtera annua. J Nat Prod 2000;63:845-7.

10. Shahat AA, Abdel-Shafeek KA, Claeys M, Apers S, Pieters L, Vlietinck AJ. A new flavonoid from Carrichtera annua. Nat ProdSci 2006;12:122-4.

11. Markham KR. Techniques of flavonoid identification. London: Academic Press; 1982.

12. Shahat AA, Apers S, Van Miert S, Clays M, Pieters L, Vlietinck AJ. Structure elucidation of three new acetylated flavonoid glycosides from Centauriumspicatum. Magn Reson Chem 2001;39:625-9.

13. Markham KR, Chari VM, Mabry J. The flavonoids: Advances in research. In: Harborne JB, Mabry TJ, editors. London: Chapman and Hall; 1982. p. 19-134.

14. Markham KR, Geiger $\mathrm{H}$. The flavonoids: Advances in research since 1986. In: Harborne JB, editor. London: Chapman and Hall; 1994. p. 441-97.

Cite this article as: Shahat $A A, A$ dbdelshafeek KA, Husseiny $H A$. Isolation and identification of a new flavonoid glycoside from Carrichtera annua $L$. seeds. Phcog Res 2011;3:151-4.

Source of Support: Nil, Conflict of Interest: None declared.

Announcement

\section{Android App}

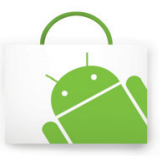

A free application to browse and search the journal's content is now available for Android based mobiles and devices. The application provides "Table of Contents" of the latest issues, which are stored on the device for future offline browsing. Internet connection is required to access the back issues and search facility. The application is compatible with all the versions of Android. The application can be downloaded from https://market.android.com/details?id=comm.app.medknow. For suggestions and comments do write back to us. 